\title{
Morphological and functional characteristics of cell culture derived from the mouse nail unit
}

\author{
Kalmukova O. O. ${ }^{1,2}$, Ustymenko A. M. ${ }^{1}$, Lutsenko T. M. ${ }^{1}$, Klymenko P. P. ${ }^{1}$, Kyryk V. M. ${ }^{1}$ \\ ${ }^{1}$ State Institute of Genetic and Regenerative Medicine NAMS of Ukraine, Kyiv, Ukraine \\ ${ }^{2}$ Educational and Scientific Centre "Institute of Biology", Taras Shevchenko National University of Kyiv, Kyiv, Ukraine \\ e-mail: olesyakalmukova@gmail.com
}

\section{ABSTRACT}

Nail unit is a complex anatomical structure that is capable of rapid growth and regeneration throughout the life. Such significant reparative potential is associated with the presence different types of stem and progenitor cells, whose biology remains one of the fundamental issues today. Taking into account the active search for new stem cell sources for cell therapy, the view of the nail unit as a potential site for the localization of undifferentiated cells with stem potency is topical problem.

PURPOSE. The study was conducted with an objective to establish the morphological, morphometric and proliferative characteristics of cultured cells isolated from the mouse nail unit.

MATERIALS AND METHODS. Primary cultures of cells were obtained from tissue sampling, which included areas of the proximal nail fold, nail matrix and onychodermis of the FVB mouse nail organ. Cells were cultured in DMEM:F12 medium with $15 \%$ fetal bovine serum during 6 passages. We determined the colony-forming activity, the population growth rate and doubling time, measured the area of cells, nuclei, and calculated the nuclear-cytoplasmic ratio. For cell morphology analysis, we used staining with Bemer's hematoxylin and eosin, Heidenhain's iron hematoxylin and May-Grünwald stain.

RESULTS. According to the morphological analysis in vitro the cells from mouse nail unit are heterogeneous with high synthetic activity and a low nuclear-cytoplasmic ratio - the features characteristic of the low-differentiated cells. The population doubling time of the culture was $80 \pm 6.5$ hours on average, the fastest growing cells were at the $4^{\text {th }}$ passage (63 \pm 7 hours). The specific growth rate for cell culture is low $(0.01 \pm 0.0007)$.

The colony forming efficiency at the $5^{\text {th }}$ passage was only $4 \%$. A significant number of colonies was small with large poorly proliferative cells, which may indicate a production of large numbers of transitional progenitor cells.

CONCLUSION. The obtained cell culture from the mouse nail unit according to the analysis of their morphology, morphometry and proliferative potential is heterogeneous and requires the further development of pure culture technologies for the detailed characterization of separate subpopulations of cells.

KEYWORDS: nail unit; nail matrix; onychodermis; cell culture; clonogenic assay

Traumatic amputation of distal phalanges of fingers is the most common type of hand injury in humans [1]. Fingers phalanges of some mammals (including mice) may partially recover after injury, while regeneration of the entire limb in mammals does not occur [2]. It is assumed that the presence of the nail provides the growth of the lost distal part of the finger [3].

The nail organ is a complex structural functional unit [4] located on the dorsal side of the distal phalanx and composed of many types of cells, most of which are of epithelial origin - epitheliocytes (hyponychium, cuticle), keratinocytes (ventral nail matrix), melanocytes, Merkel cells, immune cells (Langerhans cells) [5], onychofibroblasts [6, 7], stem cells of the nail [8]. The protective function of the nail organ is ensured by the formation of a highly keratinized nail plate that grows throughout life. This continuous renewal is dependent by the activity of the stem cells of the nail, which biology is still poorly understood. The open questions remain their localization $[11,12,13])$ and origin. 


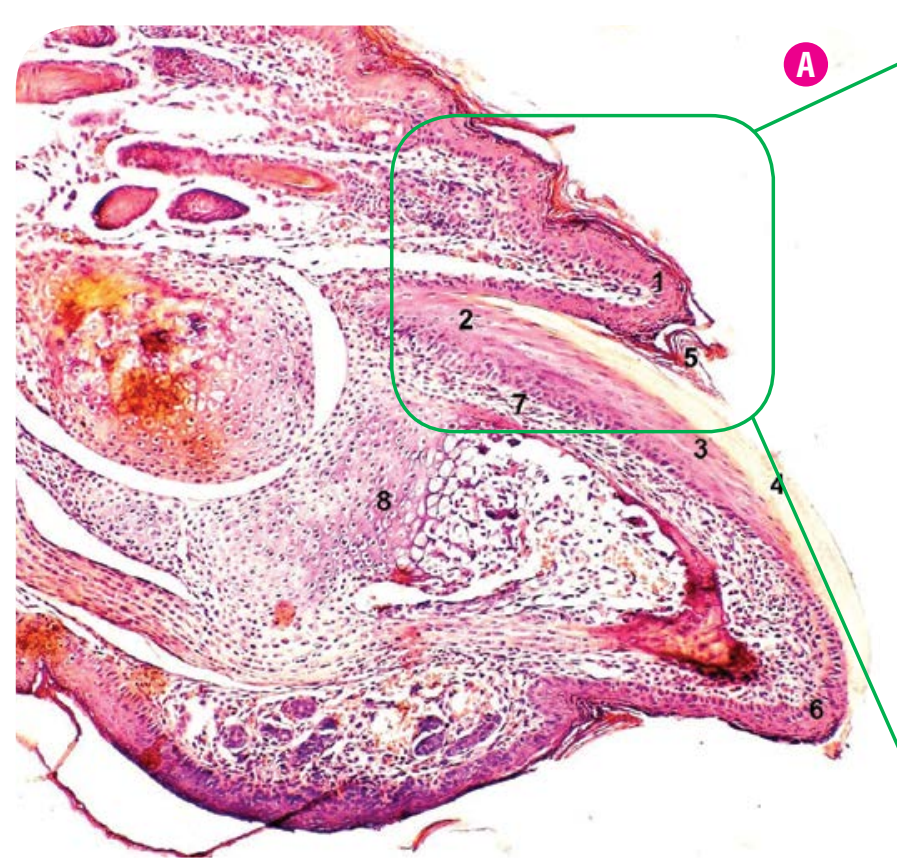

As you know, ectodermal skin appendages in mammals (hair, nails, hoof, horns and teeth [14]) develop from epithelium and neural crest (derivatives of ectoderm $[15,16]$ ) or mesenchyme (derivatives of mesoderm [17]). The presence of undifferentiated cells with high proliferative potential is demonstrated in the distal and proximal parts of the nail matrix $[9,10]$, ventral proximal nail bed [8] and onychodermis [11, 12, 13]. Among skin appendages, the most similar in structure to the nail unit is a hair follicle. Similar in their functions are hair follicles and nail matrix, hair shaft and nail plate [18]. In the hair follicle, the location of a pool of undifferentiated stem cells (bulge) that are derivatives of the neural crest $[19,20]$ is revealed, but the search for such a site in the nail organ is still ongoing.

The study of nail stem cells is very important both in the fundamental and in the applied aspect, since the search for new sources of stem cells for cell therapy is relevant today. In addition, the study of regulatory pathways for the interaction of different types of cells (keratinocytes, melanocytes, epitheliocytes, low-differentiated progenitors) of the nail unit will allow more detailed disclosure of the mechanisms of the pathogenesis of such diseases as vitiligo [21], psoriasis [22, 23]. It is known that the manifestations of these diseases are often associated with changes in nails, which may have important diagnostic value, and will allow the development of new therapies due to effects on the signaling cascade of cells.

The study was conducted with an objective to establish morphology, morphometry, self-renewal ability and proliferative potential of cultured cells derived from the mouse nail unit.

\section{MATERIALS AND METHODS}

All experiments on animals are carried out in compliance with the international principles of the European Convention for the Protection of Vertebrate Animals used for experimental and other scientific purposes (European Convention, Strasburg, 1986), Article 26 of the Law of Ukraine «On the Protection of Animals from Cruelty» (No. 3447-IV, February 21, 2006), as well as all norms of bioethics and biological safety.

The studies were performed on cell cultures obtained from FGV-C$\mathrm{Tg}$ (GFPU) $5 \mathrm{Nagy} / \mathrm{J}$ mice transgenic for green fluorescent protein (GFP) gene, aged 6-7 days. Mice were kept under the standard conditions in the vivarium of the State Institute of Genetic and Regenerative Medicine (Kyiv, Ukraine), with ad libitum access to water and food.

Obtaining and cultivation of cells from the murine nail unit. The culture of the nail unit cells (NUCs) was obtained from tissue explants,

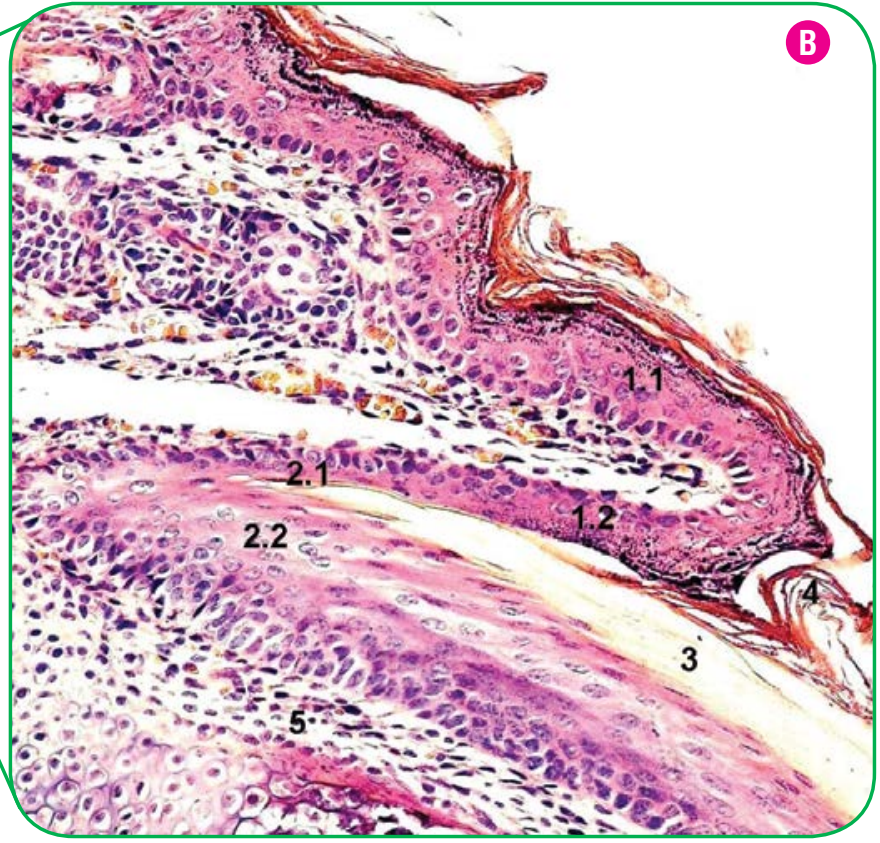

Fig. 1. Microphotography of the histological longitudinal sections of the adult mouse nail unit (hematoxylin-eosin staining, $\mathbf{A}-\times 40$, B $-\times 100$ ).

A) 1 - proximal nail fold (PNF); 2 - nail matrix (NM); 3 - nail bed; 4 - nail plate; 5 - cuticle; 6 - hyponychium; 7 - onychodermis; 8 - bone of distal phalanx.

B) 1.1 - dorsal part of PNF; 1.2 - ventral part of PNF; 2.1 - dorsal part of NM; 2.2 - ventral part of NM; 3 - nail plate; 4 - cuticle; 5 - onychodermis

which included the ventral part of the proximal nail fold (Fig. 1B-1.2), onychodermis (Fig. 1A-7, 1B-5), dorsal (Fig. 1B-2.1) and ventral (Fig. 1B2.2) parts of the nail matrix (Fig. 1). This zone was isolated from the nail unit under sterile conditions under the binocular stereoscopic microscope MBS-10. The implants were cultured in a $35 \mathrm{~mm}$ Petri dishes in DMEM:F12 (Sigma, USA) supplemented with $15 \%$ fetal bovine serum (Sigma, USA) and $40 \mu \mathrm{g} / \mathrm{ml}$ penicillin/streptomycin in a $\mathrm{CO}_{2}$ incubator Thermo 150 (Thermo, USA) at $37{ }^{\circ} \mathrm{C}, 95 \%$ humidity and $5 \% \mathrm{CO}_{2}$. Passaging of the primary NUCs culture was carried out on the $14^{\text {th }}$ day of cultivation, further subcultivation was carried out upon reaching the confluence.

Staining and morphometric analysis. After removing the culture medium, the cells were washed with phosphate buffered saline (PBS) and fixed in $96 \%$ ethanol for 20 minutes. For morphological analysis, the cells were stained with May-Grünwald azur-eosin stain for 20 minutes.

To characterize the NUCs processes and cytoskeleton, the culture was stained with Heidenhain's iron hematoxylin. After fixation, the samples were washed with PBS, treated with $2.5 \%$ ammonium iron (III) sulfate for 10 minutes at $37^{\circ} \mathrm{C}$ in a thermostat, after which they were stained with Heidenhain's iron hematoxylin for 10 minutes at $37^{\circ} \mathrm{C}$ in a thermostat and washed in PBS and in water.

For morphometric analysis (counting the number of nuclei, area of nucleus and cells, as well nuclear-cytoplasmic ratio), staining with Bemer's hematoxylin and eosin was used, which gives a bright contrast and clearly distinguishes the cytoplasm from the nucleus. Fixed and dried NUCs were stained with Bemer's hematoxylin for 5-10 min, and then kept for 10-15 minutes in water, after that they were stained with eosin for $3 \mathrm{~min}$.

Vital microscopy and cytological analysis were performed using an inverted fluorescence microscope IX 71 (Olympus, Japan), with a digital camera DP-20 and QucikPHOTO MICRO software (Promicra, Czech Republic). Morphometric analysis was performed on digital microphotographs using ImageJ v. 1.45 software (National Institutes of Health, USA). 

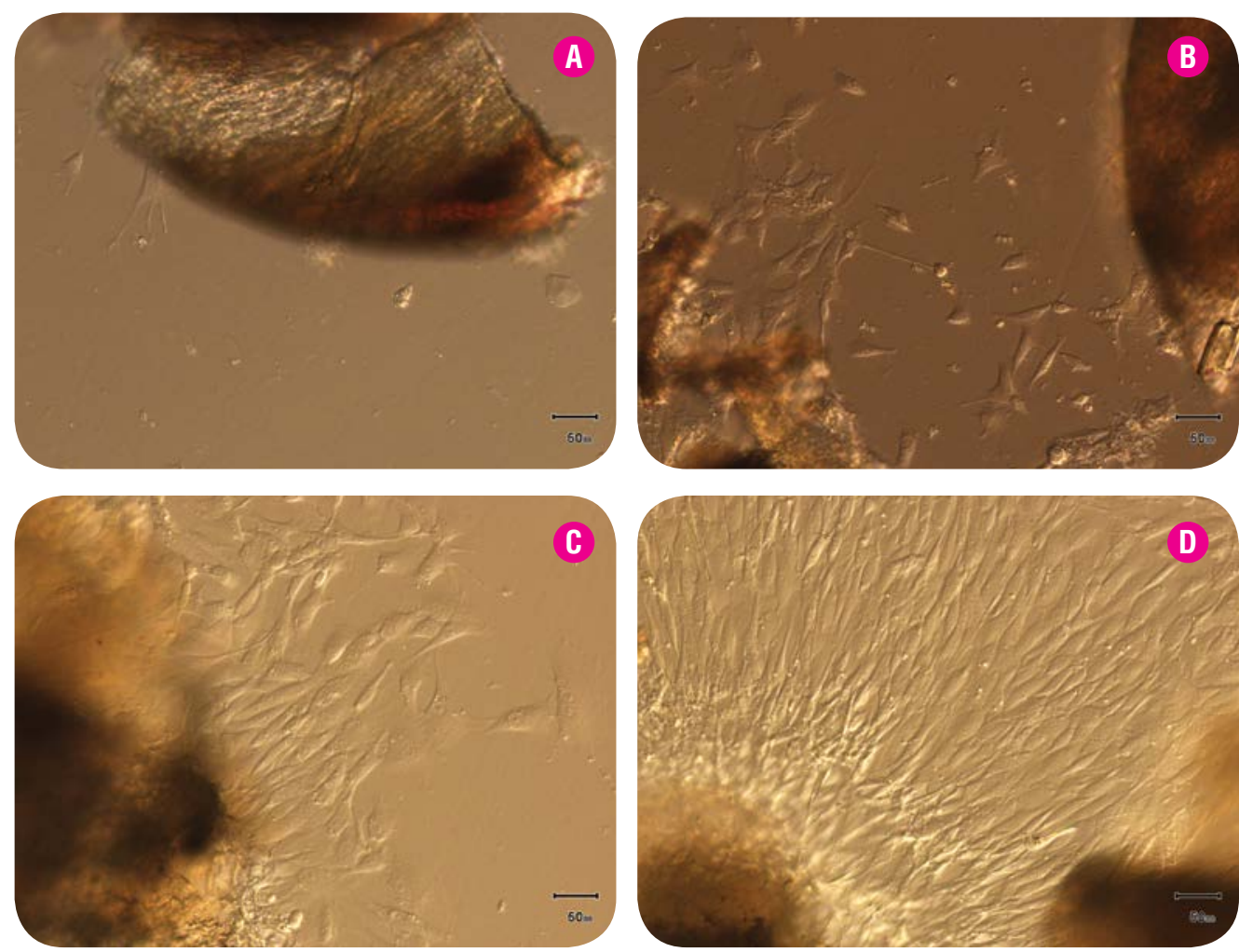

Fig. 2. Microphotographs of cell culture from mouse nail unit ( $\times 40$, phase-contrast microscopy):

A - the $3^{\text {rd }}$ day of cultivation; $B$ - the $6^{\text {th }}$ day of cultivation; $\mathrm{C}$ - the $9^{\text {th }}$ day of cultivation; D - the $12^{\text {th }}$ day of cultivation.
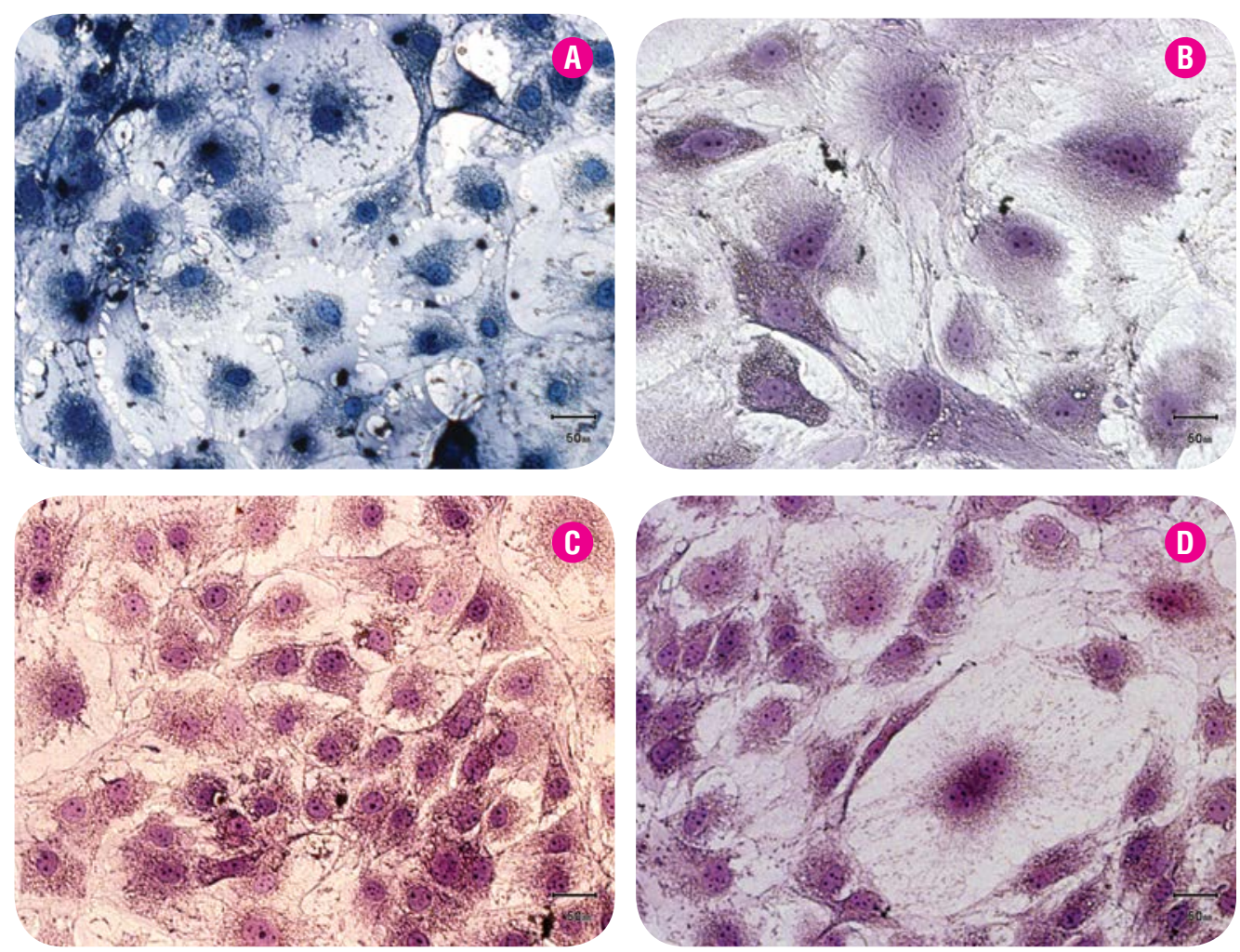

Fig. 3. Micrographs of the mouse nail unit cell culture $(\times 100)$ :

A - Heidenhain's iron

hematoxylin staining (passage 2); B - May-Grünwald staining (passage 2);

C - Bemer's hematoxylin and eosin staining (passage 1): D - Bemer's hematoxylin and eosin staining (passage 4)

Clonogenic assay and self-renewal ability. The NUCs, starting from the 2nd passage, were seeded in a $35 \mathrm{~mm}$ Petri dishes, $12 \cdot 10^{4}$ per one dish $\left(12.5 \cdot 10^{3}\right.$ cells per $\left.\mathrm{cm}^{2}\right)$, and cultivated in the medium DMEM:F12 at $5 \% \mathrm{CO}_{2}$ for a further 7 days. The medium was changed every 48 hours. The cells were taken with $0.25 \%$ trypsin solution with EDTA and were counted in Goryaev chamber. We calculated the population doubling time and the growth rate according to the standard formulas [24].
For the clonogenic assay (counting of colony-forming units), a serial dilution method in a 96-well plate with an initial concentration of $2 \cdot 10^{4}$ cells $/ \mathrm{ml}$ or $4 \cdot 10^{3}$ cells in the first well $(200 \mu \mathrm{l})$ was used, which was ultimately brought to dilution in 1 cell per well [25]. The final largest number of NUCs in the well was $1 \cdot 10^{3}$, which decreased in geometric progression to 1 . After 10 days in culture, cells were fixed with $4 \%$ paraformaldehyde solution and stained with May-Grünwald stain. 


\section{Population doubling time, hours}

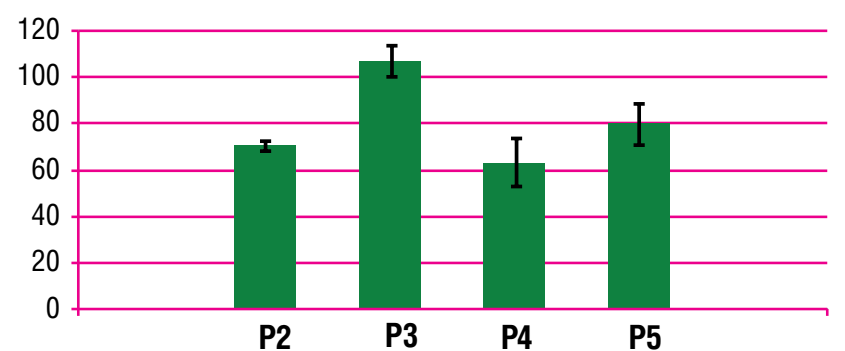

Popilation growth rate, a.u.

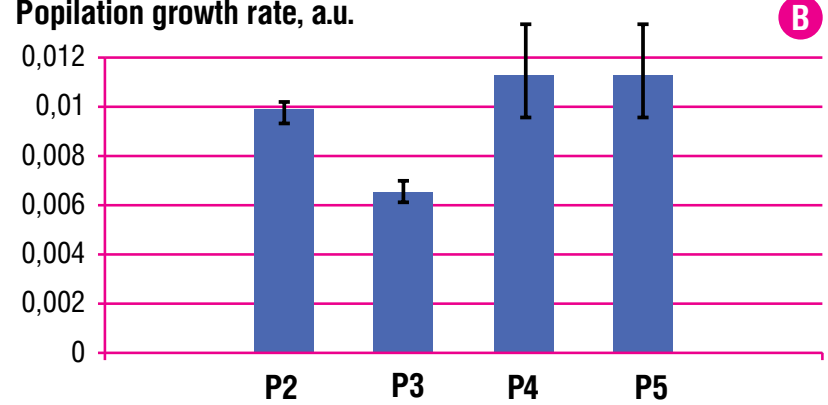

Fig. 4. Dynamics of the population doubling time (A) and population growth rate (B) of the mouse nail unit cell culture at 2, 3, 4 and 5th passages.

Statistical analysis. The statistical analysis of the obtained results was carried out using the Statistica 10 (StatSoft, USA) and MS Excel (Microsoft, USA) software. Morphometry was performed using ImageJ v. 1.45 software. The results are presented as $M \pm m$ (mean \pm standard error of the mean).

\section{RESULTS AND DISCUSSION}

On the $3-4^{\text {th }}$ day of culture, migration and active proliferation of fibroblast-like cells began from the explants of the nail unit (Fig. 2). Obtained mouse NUCs reached confluent monolayer on the $14^{\text {th }}$ day of cultivation on the average. Most cells had fibroblast-like morphology with bipolar processes, but there were widespread cells of polygonal form without processes, as well as rounded, not attached cells.

\section{STAINING AND MORPHOMETRIC ANALYSIS.}

The NUCs were characterized by the nucleus of the correct round form at the presence of several clearly visible nucleoli (Fig. 3). After staining by various methods in the perinuclear cytoplasm of many cells, there are fine dispersed grains - a sign of abundant granular endoplasmic reticulum and active protein synthesis. By the form, the NUCs are round, polygonal and fibroblast-like with long bipolar processes. Such heterogeneity of cells form was also noted in other previous studies in the cultivation of human nail matrix (polygonal and spindle-shaped cell morphology). [26] All cells have numerous short and thin processes, most of which form contact with surrounding cells.

The obtained morphometric data (Table 1) showed an increase in the area of NUCs in 4.5 times and nucleus in 4 times at subsequent passages (comparison was made on 1 and 4 passages). However, this increase is not proportional, since the nuclear-cytoplasmic ratio (NCR) on these passages did not change and remained stable low and averaged $0.071 \pm 0.01$. Moreover, such data regarding the low value of NCR are corresponding with the results of another experiment on the cultivation of human nail matrix [27]: besides low NCR, a high level of euchromatin to heterochromatin was shown by electronic microscopy, which indicates the high activity of the synthesis processes in the nucleus. In our work, the increased number of nucleoli (an average of 4 per nucleus versus 1-2 generally) evidenced the significant level of synthesis activation.

Table 1. Data of the morphometric analysis of the cell culture from mouse nail unit.

\begin{tabular}{|l|c|c|c|c|}
\hline PASSAGE & $\begin{array}{c}\text { CELL'S AREA } \\
\left(\mu \mathrm{m}^{2}\right)\end{array}$ & $\begin{array}{c}\text { NUCLEUS } \\
\text { AREA }\left(\mu \mathrm{m}^{2}\right)\end{array}$ & $\begin{array}{c}\text { NUCLEAR- } \\
\text { CYTOPLASMIC } \\
\text { RATION }\end{array}$ & $\begin{array}{c}\text { NUMBER } \\
\text { OF } \\
\text { NUCLEOLI }\end{array}$ \\
\hline P1 & $1032 \pm 61$ & $62 \pm 3$ & $0.078 \pm 0.004$ & $4 \pm 0.2$ \\
\hline $\mathbf{P 4}$ & $5235 \pm 595$ & $239 \pm 13.5$ & $0.065 \pm 0.003$ & $3 \pm 0.2$ \\
\hline
\end{tabular}

\section{$\%$ colony per 1 cell}

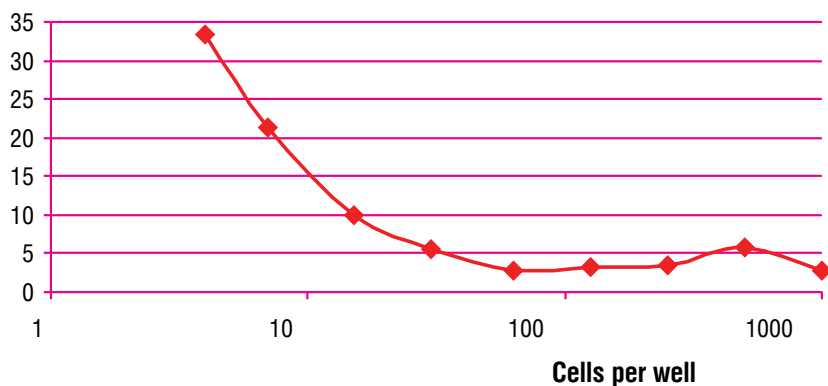

Fig. 5. Clonogenic assay of the mouse nail unit cell culture at the 5th passage.

PROLIFERATIVE POTENTIAL AND SELF-RENEWAL ABILITY.

The population doubling time of the NUCs culture (Fig. 4A) averaged 80 \pm 6.5 hours, with the fastest cells growing at the $4^{\text {th }}$ passage ( $63 \pm 7$ hours). The growth rate of the cell culture (Fig. 4B) is generally low $(0.01 \pm 0.0007)$, which may be due to the culture of the NUCs at once from several zones of the probable location of the low-differentiated cells, as well as with their small number in comparison with the amount of other cells.

Clonogenic assay was performed at the $5^{\text {th }}$ passage, which could have had an effect on the colony forming efficiency, since it was only $4 \%$ (Fig. 5), the highest frequency of colonies ( $33 \pm 3.6 \%$ ) per cell was observed at a cell concentration of 4 cells per well. A significant number of colonies was small with large poorly proliferative cells, which may indicate a production of large numbers of transitional progenitor cells.

In general, the data presented in the morphological and morphometric analysis of primary cultures of cells from the murine nail unit are only the initial stage of further detailed and thorough study of this type of cells. Heterogeneity of these cell population in vitro confirms the complexity of the histological structure of the nail unit and the presence of many types of cells in it, which may differ in morphological characteristics, proliferative activity, surface and intracellular markers, responsible for intercellular interaction and the realization of specific functions, including reparative potentials [29,30]. Therefore, the issue of obtaining pure cultures of cells derived from specific anatomical areas of the nail unit, in particular, from the proximal nail fold, nail matrix and onychodermis, remains actual.

\section{CONCLUSIONS}

The obtained cell culture from the mouse nail unit according to the analysis of their morphology, proliferative potential and the results of morphometry is heterogeneous and requires the further development of pure culture technologies for the detailed characterization of separate subpopulations of cells. 
1. Sorock G, Lombardi D, Hauser R, et al. Acute traumatic occupational hand injuries: type, location, and severity. J Occup Environ Med. 2002; 44: 345-51.

2. Rinkevich Y, Maan Z, Walmsley G, et al. Injuries to appendage extremities and digit tips: A clinical and cellular update. Dev Dyn. 2015; 244(5): 641-50.

3. Lehoczky J. Are fingernails a key to unlocking the puzzle of mammalian limb regeneration? Experimental Dermatolog. 2016; doi: 10.1111/exd.13246

4. Kalmukova 00. Stem cells in nail unit of mammalians. Cell and Organ Transplantology. 2016; 4(1):138-143. doi: 10.22494/COT.V4l1.1

5. Ito $T$, Ito $N$, Saathoff $M$, et al. Immunology of the human nail apparatus: the nail matrix is a site of relative immune privilege. J Invest Dermatol. 2005; 125: 1139-148.

6. Sellheyer $K$, Nelson $P$. The concept of the onychodermis (specialized nail mesenchyme): an embryological assessment and a comparative analysis with the hair follicle. J Cutan Pathol. 2013; 40: 463-471.

7. Lee KJ, Kim WS, Lee JH, et al. CD10, a marker for specialized mesenchymal cells (onychofibroblasts) in the nail unit. J Dermatol Sci. 2006; 42: 65-67.

8. Sellheyer K. Nail stem cells. JDDG. 2013; 1103: 235-39.

9. Nakamura $M$, Ishikawa 0 . The localization of label-retaining cells in mouse nails. J Invest Dermatol. 2008; 128: 728-30.

10. Takeo M, Chou W, Sun Q, et al. Wnt activation in nail epithelium couples nail growth to digit regeneration. Nature. 2013; 499: 228-32.

11. Lee DY, Park JH, Shin HT, et al. The presence and localization of onychodermis (specialized nail mesenchyme) containing onychofibroblasts in the nail unit: a morphological and immunohistochemical study. Histopathology. 2012; 61(1): 123-30.

12. Park JH, Kim JH, Lee JH, et al. Onychodermis (specialized nail mesenchyme) is present in ectopic nails. J Cutan Pathol. 2013; 40: 600-602.

13. Perrin $C$. The nail dermis: from microanatomy to constitutive modelling. Histopathology. 2015; 66(6): 864-72.

14. Naveau A, Seidel K, Klein OD. Tooth, hair and claw: comparing epithelial stem cell niches of ectodermal appendages. Experimental cell research. 2014; 325(2): 96-103.

15. Narytnyk A, Gillinder $K$, Verdon $B$, et al. Neural crest stem cell-specific deletion of the Pygopus2 gene modulates hair follicle development. Stem Cell Reviews and Reports. 2014; 10(1): 60-68.

16. Soukup V, Epperlein HH, Horacek I, et al. Dual epithelial origin of vertebrate oral teeth. Nature. 2008; 455(7214): 795-98.

17. Okazaki $M$, Yoshimura $K$, Fujiwara $H$, et al. Induction of hard keratin expression in non-nail-matrical keratinocytes by nail-matrical fibroblasts through epithelialmesenchymal interactions. Plastic and reconstructive surgery. 2003; 111(1): 286-90.

18. Achten G. Normale Histologie und Histochemie des Nagels. In: Jadassohn J: Handbuch der Haut- und Geschlechtskrankheiten.Bd 1. Berlin: Springer, 1968: 339-76.

19. Sieber-Blum M, Grim M, Hu YF, et al. Pluripotent neural crest stem cells in the adult hair follicle. Developmental Dynamics. 2004; 231(2): 258-69.

20. Fernandes KJ, McKenzie IA, Mill P, et al. A dermal niche for multipotent adult skin-derived precursor cells. Nature cell biology. 2004; 6(11): $1082-93$.

21. Anbar T, Hay RA, Abdel-Rahman AT, et al. Clinical study of nail changes in vitiligo. Journal of cosmetic dermatology. 2013; 12(1): 67-72.

22. Haber $R$, Khoury $R$, Kechichian $E$, et al. Splinter hemorrhages of the nails: a systematic review of clinical features and associated conditions. International Journal of Dermatology. 2016; 55(12): 1304-310.

23. Schons KR, Knob CF, Murussi N, et al. Nail psoriasis: a review of the literature. An Bras Dermatol. 2014; 89(2): 312-17.

24. Available: http://www.doubling-time.com/compute.php

25. Cell cloning by serial dilution in 96 well plates, protocol. John A. Ryan. Corning. Available: http://www.level.com.tw/html/ezcatfiles/vipweb20/img/img/34963/32Single_cell_cloning_protocol.pdf

26. Kitahara T, Ogawa H. Cultured nail keratinocytes express hard keratins characteristic of nail and hair in vivo. Arch Dermatol Res. 1992; 284(4): 253-56.

27. Picardo M, Tosti A, Marchese C, et al. Characterization of cultured nail matrix cells. J Am Acad Dermatol. 1994; 30: 434-40.

28. Quintanilla RHJr, Asprer JS, Vaz C, et al. CD44 is a negative cell surface marker for pluripotent stem cell identification during human fibroblast reprogramming. PLoS One. 2014; 9(1): e85419.

29. Kyryk V, Kuchuk O, Butenko G. Cultivation of cells with stem potential from nail matrix. Abstracts of the World Conference on Regenerative Medicine, November 2-4, 2011, Leipzig, Germany. Regenerative Medicine. 2011; 6(6), Suppl. 2:216-217.

30. Rinkevich Y, Lindau $P$, Ueno H, et al. Germ-layer and lineage-restricted stem/progenitors regenerate the mouse digit tip. Nature. 2011; 476(7361): 409-13.

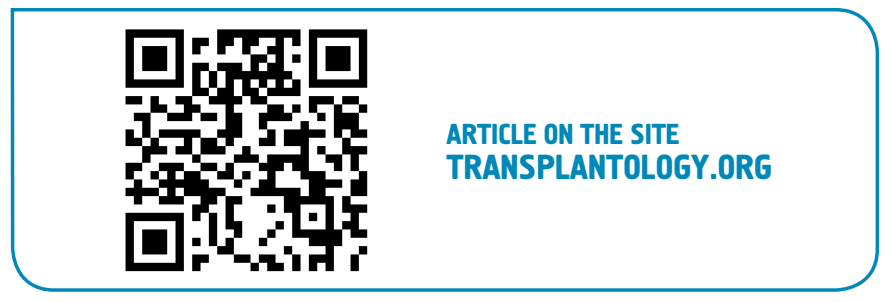

The authors indicate no potential conflicts of interest.

Received: April 14, 2017

Accepted: May 22, 2017 